\title{
GEBCO GRIDDED BATHYMETRIC DATASETS FOR MAPPING JAPAN TRENCH GEOMORPHOLOGY BY MEANS OF GMT SCRIPTING TOOLSET
}

\author{
Polina LEMENKOVA $\mathbb{B}^{*}$ \\ Analytical Center, Tagansky District, 115035 Moscow, Russian Federation
}

Received 14 September 2019; accepted 15 September 2020

\begin{abstract}
The study investigated geomorphology of the Japan Trench located east of Japan, Pacific Ocean. A high-resolution GEBCO Gridded Bathymetric Dataset was used for modeling, mapping and visualization. The study aimed to compare and analyse variations in the geomorphic structures of the two parts of the trench and to visualize variations in the geological, geophysical and bathymetric settings. Technically, the cartographic work was performed using scripting based on the Generic Mapping Toolset (GMT). Modelled cross-sectioning orthogonal profiles transecting the trench in a perpendicular direction were automatically digitized and graphed in the two segments. The results of the bathymetric analysis shown that the southern part is shallower: with deeper values in absolute (139 samples between -7000 to $-8000 \mathrm{~m}$ ) and statistical records (the most frequent values are within -5500 to $-5800 \mathrm{~m}$ ) comparing to the northern segment $(-5300$ to $-5500 \mathrm{~m}$ ). The geomorphological analysis shows a more complicated relief in the northern part of the trench, which has a higher seismic activity. The southern part has a gentler slope on the Honshu island side. The geoid modeling along the trench ranges in 0-20 mGal. The highest values are recorded by the Honshu Island ( $>40 \mathrm{mGal}$ ). The rest of the area has rather moderate undulations $(20-40 \mathrm{mGal})$. The free-air marine gravity of the Sea of Japan is $<40 \mathrm{mGal}$. The results include $2 \mathrm{D}$ and $3 \mathrm{D}$ graphical models, thematic cartographic maps, spatial and statistical analysis of the Japan Trench geomorphology. Tested GMT functionality can be applied to future regional bathymetric modeling of the ocean trenches. All presented maps and graphs are made using GMT scripting toolset.
\end{abstract}

Keywords: GMT, cartography, geoinformatics, geospatial analysis, Japan Trench.

\section{Introduction}

Bathymetric mapping and geomorphic modelling of the deep-sea trenches is complicated to visualize and assess, since they are the deepest areas on the Earth. In view of this, the application of the advanced mapping using computer assisted cartography and is of high importance.

Mapping and modelling geomorphology of the deepsea trenches include the diverse methods for visualization of the bathymetric data. These can include the traditional GIS (e.g. ArcGIS, Map INFO, Erdas Imagine for raster grids visualization) and advanced scripting approach, such as a GMT. Current study selected a GMT scripting toolset as a main instrument. The GMT enables to perform both thematic mapping and graphical modelling (including statistical analysis) with a high quality output of maps, statistical graphs and models. Free-of-charge and open source GMT does not require expensive investments, comparing to the commercial GIS software.
The research aim of this study is to visualize, map and model geomorphology of the Japan Trench in the two different parts: the southern and the northern ones. With this aim, a digitizing of the cross-sectional profiles was performed using the GMT main module 'grdtrack. The GMT-based mapping and digitizing is technically based on the scripting approach that consist, by analogue with programming languages, in a sequence of codes taken together in a script. Running each GMT script enables to produce a map, model or to perform a statistical analysis. Comparing to the manual digitizing of the profiles (e.g. in a QGIS or an ArcGIS) the procedure of digitizing in GMT was much less time consuming, which is a clear advantage of this cartographic toolset over the traditional GIS.

The techniques for the bathymetric mapping, comparing to the land areas, are more complicated due to the unreachable study object. The deep ocean areas can only be mapped using remotely sensing methods, without direct observations (e.g. theodolite measurements or landbased in-situ assessments). This has led to a situation that

*Corresponding author. E-mail: pauline.lemenkova@gmail.com 


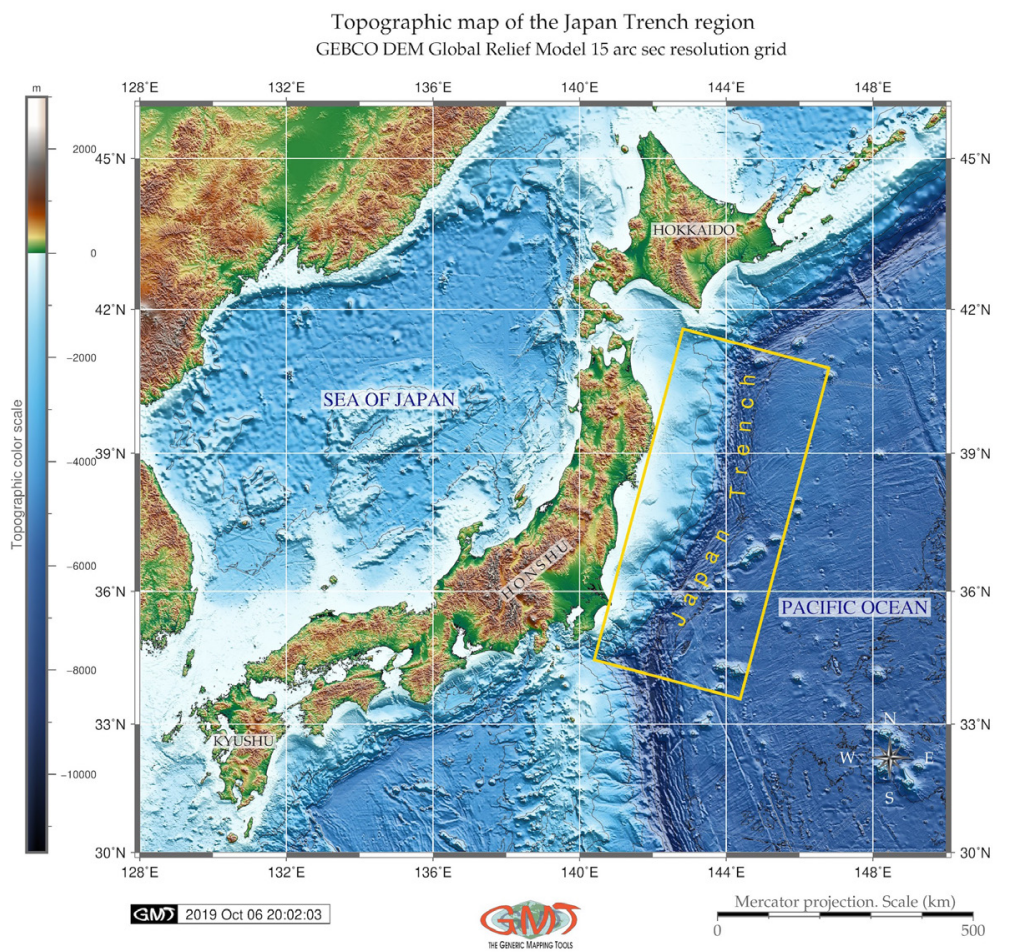

Comparison of the topographic data resolution: selected southern fragment of the Japan Trench
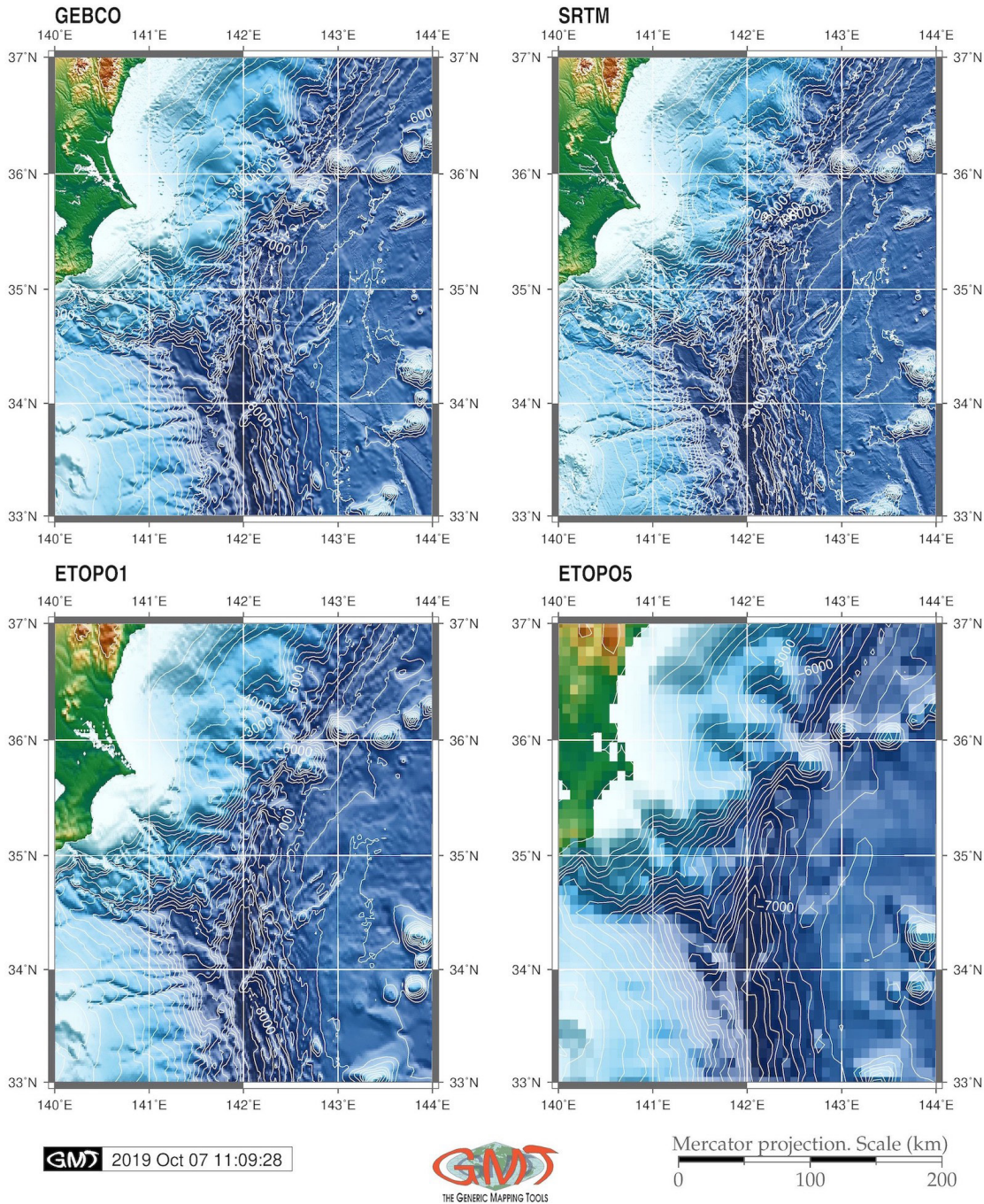

Figure 1. Topographic map of the Japan Trench region
Figure 2. Comparison of various topographic datasets: GEBCO, SRTM, ETOPO1 and ETOPO5 
mapping oceanic seafloor requires much detailed, highresolution and reliable input data sets (e.g. GEBCO or SRTM) compared to the land areas. Unlike with the land maps, the seafloor areas cannot be checked through the direct observations or the theodolite-supported fieldwork. Therefore, using high precision data sets is crucial for the reliable marine mapping.

The comparison of the data sets in this work shown that the ETOPO5 demonstrated poor spatial resolution. For example, small-scale seamounts and other bathymetric objects, important for the geomorphic analysis of the whole study area, may by neglected in the bathymetric mapping based on the ETOPO5 due to the low spatial resolution ( 5 arc minutes). The ETOPO1 has a better precision and can in principle be used in a bathymetric mapping and modelling. However, the ETOPO1 m resolution map may produce minor errors when compared with GEBCO and SRTM. Hence, the best precision is demonstrated by GEBCO and SRTM grids, that can be used concurrently, since both have a 15 arc second resolution. In the current study, the GEBCO dataset was used as a main dataset. The specific study object of this work is a Japan Trench described below in the following sections.

The structure of the paper consists of the four sections, besides the introduction, and the eleven figures. The introduction presents the focus and goal of the research, briefly mentions the selected tools and datasets and outlines the manuscript. Section 1 (Study area description) summarizes the geographic and geological setting of the eastern Japan, region, Honshu Island and the Japan Trench. Specifically, it describes the geographic location, tectonics, geologic setting, seismicity and geomorphology in several sub-sections 1.1. to 1.5, respectively. Section 2 (Materials and Methods) includes the following subsections: '2.1. Data' where is describes the datasets in details pointing at their advantages, '2.2. Digital Elevation Model (DEM)' details principles and applications of DEM as a basis for mapping, '2.3. GMT methodology' presents the approach of scripting cartographic techniques, '2.4. Cross-section transects' introduces the applications of the machine learning methods for automatic digitizing in cartography, '2.5. Statistical analysis' formulates the approach of the statistical data processing by GMT, '2.6. Mathematical modelling' describes the applied approximation methods of modelling curves. Section 3. Results presents the findings of this research. Last section. Conclusion summarizes the problem of mapping of the deep-sea trenches and presents the perspectives of the machine learning and advanced cartography for processing high-resolution datasets in such unreachable areas of the Earth.

\section{Study area description}

\subsection{Geographic location}

The study area is located in western part of the Pacific Ocean, eastwards off Japan (Figure 1). The geologic and tectonic settings in the region of the Japan Trench are strongly influenced by the subduction of the Pacific Plate beneath northeastern Japan and North American plate along the Japan Trench (Figure 3), which is well described in the previous works (von Huene \& Lallemand, 1990). The region of the Japan Trench is a convergent zone associated with many earthquakes (Yoshii, 1979). It belongs

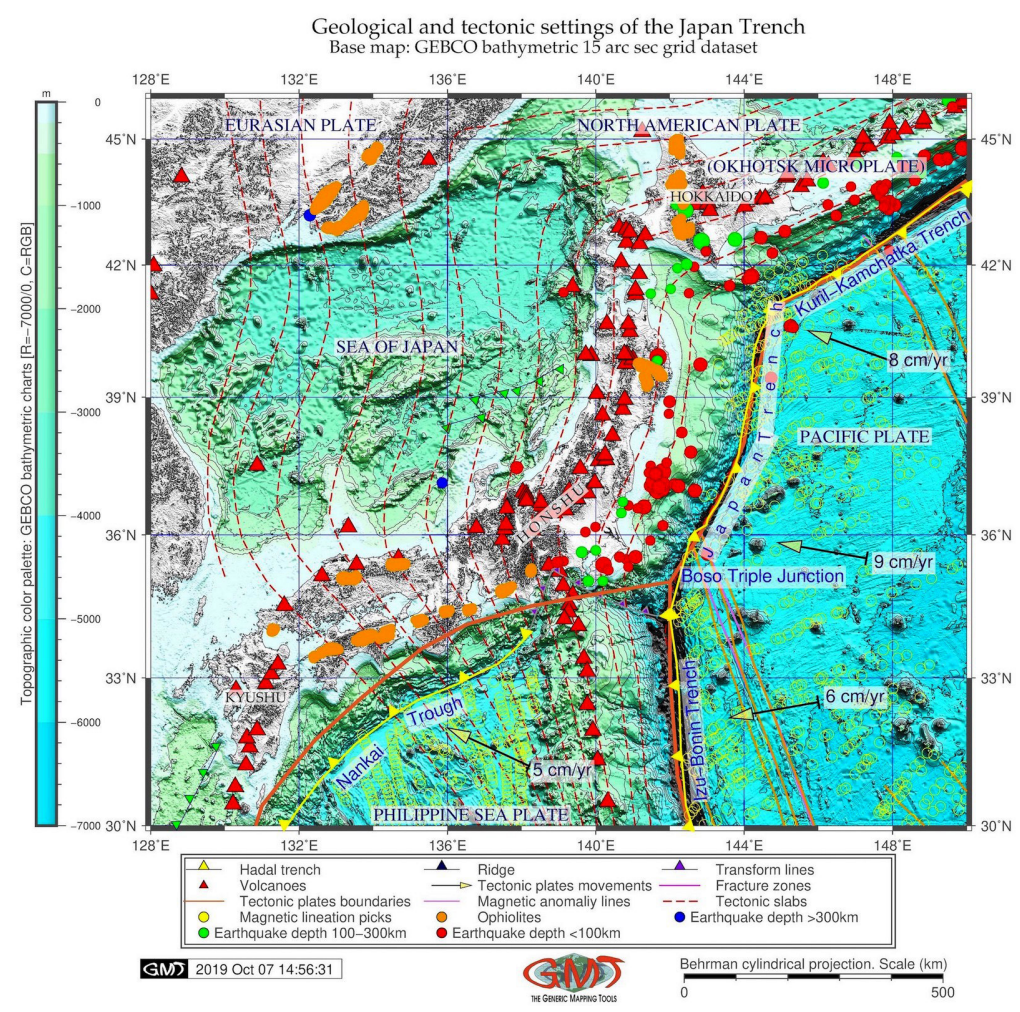

Figure 3. Geological map of the Japan Trench area 
to the circum-Pacific seismic belt (a.k.a. 'Ring of Fire') where the large earthquakes originate within the areas of sedimentation on upper forearc slopes (Arai et al., 2014).

\subsection{Tectonics}

The structure of the trench presents a typical arc-trench system (Ludwig et al., 1966). In terms of the tectonic geomorphology, the arc-trench system is a type of the mobile belts with bathymetric and topographic relief formed under the impact of the tectonic plates subduction, active volcanism, repetitive earthquakes and orogenesis. The geological complexity of the Japan Trench results in a high seismicity of the area, which is well studied in previous works (Nakamura et al., 2013; von Huene \& Culotta, 1989; Lin et al., 2016; Boston et al., 2017). The geology of Japan trench-arc system consists of the Jurassic to Neogene accretionary prisms and Neogene to Quaternary sedimentary and volcanic rocks caused by the periods of volcanism during the opening of the Sea of Japan in the middle Miocene (Wakita, 2013).

\subsection{Geologic setting}

The Cretaceous-Paleogene granitic rocks are exposed in several regions, especially on the fore-arc side. The high seismicity of the region can be illustrated by the several large interplate earthquakes that have affected the Tohoku region along the Japan Trench during the last century
(Yagi et al., 2012). Because the Japan Trench is located on the tectonic plates subduction zone, the earthquakes here belong to the largest and the most destructive in the world (Janssen et al., 2015). Many open cracks on the diatomaceous clayey sediment surfaces of oceanward slopes of the northern Japan Trench were detected by Ogawa et al. (1997). The surface of the seabed outside the cracks (i.e. normal seabed) appears to be coated by ferroman-ganese oxides (Ito \& Ogawa, 1994), and is overlain by fine pelagic mud, containing dominantly diatoms, silicoflagelates, radiolarians and sponge spicules, together with a considerable amount of detrital quartz and ash fragments (Ogawa et al., 1997).

\subsection{Seismicity}

The northern and southern parts of the Japan Trench demonstrate variations in their geologic features with heterogeneously distributed seismicity around the trench (e.g. Kawakatsu \& Seno, 1983). The most of the large earthquakes with magnitudes over 7 occurred in the northern forearc region of the trench. For example, the TohokuOki earthquake of 2011 is the largest earthquake that took place in forearc region of the Northeast Japan subduction zone, west off the Japan Trench (Lay et al., 2011; Ikehara et al., 2016), through the shallow part of the subduction zone to the seafloor surface. It triggered a devastating tsunami with massive damages along the northeast coast of Honshu, Japan (Janssen et al., 2015).

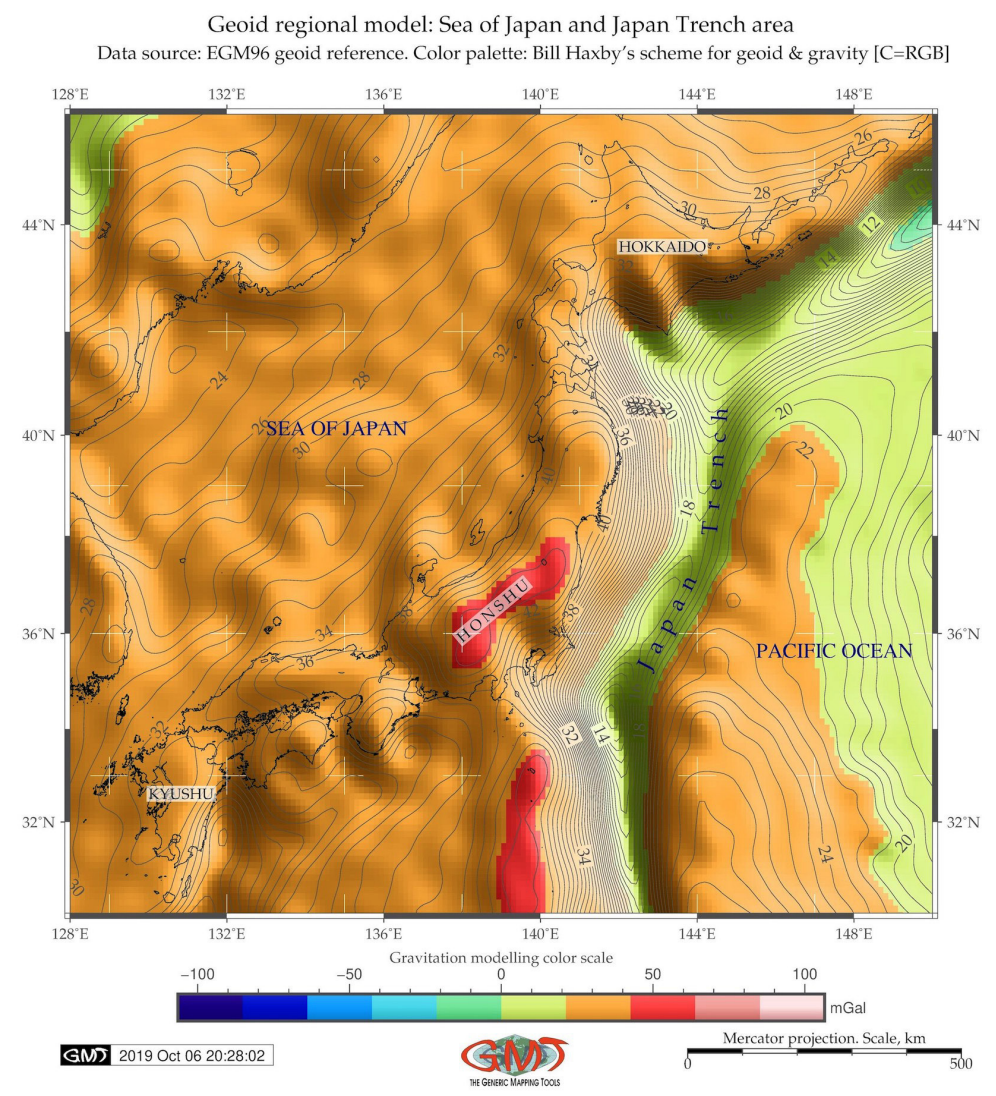

Figure 4. Geoid model of the Japan Trench area 
The southern part of the trench is seismically more 'quiet': no large earthquakes were recorded during recent centuries (Miura et al., 2005), except for the 1938 Shioyaoki earthquake (Abe, 1977). The subduction zone characterizes the northern part of the trench (Tsuru et at., 2000). In a $60 \mathrm{~km}$ buffer gap off the trench axis, a decollement structure with soft sediments is located. The zone of this structure between the two tectonic plates decouples shear stresses, which in turn forms an aseismic zone. Seismic investigations of the Japan Trench axis furthermore shown (Bose et al., 2015) variations in the frictional resistance along a decollement on the structural development of the frontal wedges near the subduction zones.

The observed slope sediments between the inner and outer wedge might have accumulated during the growth of the supercritical wedge. Seismic surveys indicate (Kodaira et al., 2012) that the shallow areas at the site of the Tohoku earthquake experienced a significant deformation. Moreover, during this event multiple faults slipped above and below the pelagic clay layer (Rabinowitz et al., 2015). Comparing the two devastating earthquakes, the 1968 Tokachi-Oki and the 1994 Sanriku-Haruka-Oki, the two distinct heterogeneities along the plate boundary at $40^{\circ} 10^{\prime} \mathrm{N}$, located exactly at the southern boundary of the two earthquakes were detected (Hayakawa et al., 2002).

\subsection{Geomorphology}

Geomorphic landforms undergo the significant deformations due to the direct effect of the plate tectonics triggering the earthquake events. It further explains the coincidence of the focal regions and the structure with slower velocities in the lower crust. The subduction of the seamount chain penetrating to the Pacific Plate possibly take place. It can further create the irregular geomorphic landforms. When these seamounts subduct deep, they collapse due to the mechanical affects from the free water released by a collapsing seamount. In turn, it might rise into the island-arc mantle and the lower crust. This brief illustration of the deep correlation between the tectonic and geological processes finally results in the actual land forms and geomorphological patterns.

\section{Materials and methods}

\subsection{Data}

The objectives and goals of this paper are follows: 1) to visualize, map and compare several bathymetric grids (GEBCO, SRTM and ETOPO1 and ETOPO5) aimed to select the high-quality topographic data with detailed resolution; 2) using the data selected in the previous step, to map and analyse the geological, tectonic and geophysical characteristics controlling the geomorphology of the trench; 3) to perform automatic digitizing of the crosssection profiles aimed at the investigation of the geomorphic structure and shape of the Japan Trench in its two segments: the southern and the northern; 2) to compare the geomorphic structure of the Japan Trench obtained as a result of the data analysis and GMT based profile modeling and to do a statistical analysis.

Following such a workflow, the first step of the present study consisted in selecting a dataset. The input data and materials used in the geospatial research should always be

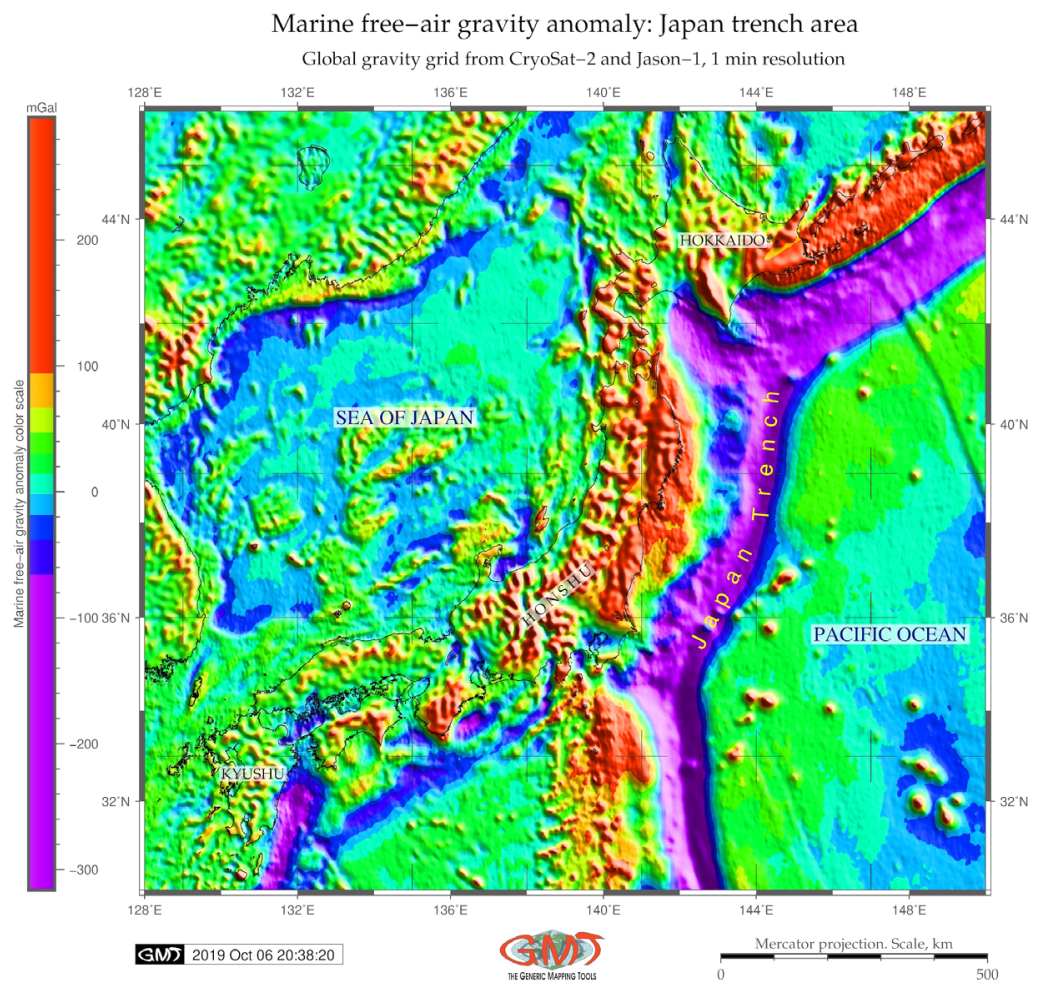

Figure 5. Free-air gravity model of the Japan Trench area 
assessed on their accuracy (Smith, 1993; Wessel \& Watts, 1988). Estimation of the data accuracy enables to take a decision on whether or not these data can be used for modeling and mapping. Therefore, current study is based on the high-resolution bathymetric dataset GEBCO, https://www.gebco.net/ (GEBCO Committee, 2016; Monahan, 2004).

The GEBCO project aimed at the high precision mapping of the ocean seafloor originated as early as origins at the beginning of the 20th century and since then up to now have been developed by several oceanographic organizations (Mayer et al., 2018; Weatherall et al., 2015). Regular updates of the GEBCO dataset grid, R/V based bathymetric observation and hydrographic meetings (Ferrini, 2018) maintain both the accuracy of GEBCO grids (Tani, 2017) and the actuality of the names of the submarine objects (Stagpoole et al., 2016). There are other data sets commonly used in the geographic studies (SRTM, ETOPO1, ETOPO5). However, the GEBCO resolution of the 15 seconds grids gives a truly reliable accuracy comparing to the other raster data (Figure 2). Using GEBCO grid was done through the GMT scripting toolset using existing methodologies and technical documentation available both on GEBCO (Kumar, 2013) and on the GMT scripting toolset (Wessel et al., 2013).

The next research part included mapping and modelling performed by means of the GMT cartographic scripting toolset. The aim was to model variations in the geomorphology of the Japan Trench two different segments, and to visualize changing geophysical settings and geological conditions of the Japan Trench area.

Coastal borders on all the maps were based on the GSHHG to visualize the thematic maps. The 3D map of the Pacific Ocean (Figure 6) was done using ETOPO5 5 grid originally developed by NOAA. The geoid data grids used for this study and retrieved from the website geoid data grids based on the GPS based EGM96 and WGS 84 reference system. The model is based on the fully-normalized, unitless spherical harmonic coefficients. The data are made public by the American centres: NIMA, NASA, GSFC, and the Ohio State University.

\subsection{Digital Elevation Model (DEM)}

The research is principally based on the DEM applications in marine geology. The DEM consists of a matrix of digital values containing elevations and coordinates. A visualization of DEM is presented in form of a contoured topographic map with additional relief shading and colour palette assignment using GMT methods. The elevations are highlighted using various colours, for instance, an artificial colour palette for a $3 \mathrm{D}$ topographic model as oblique views based on DEM in Figure 6. The Figure 6 presents a synthetic visual image of the terrain

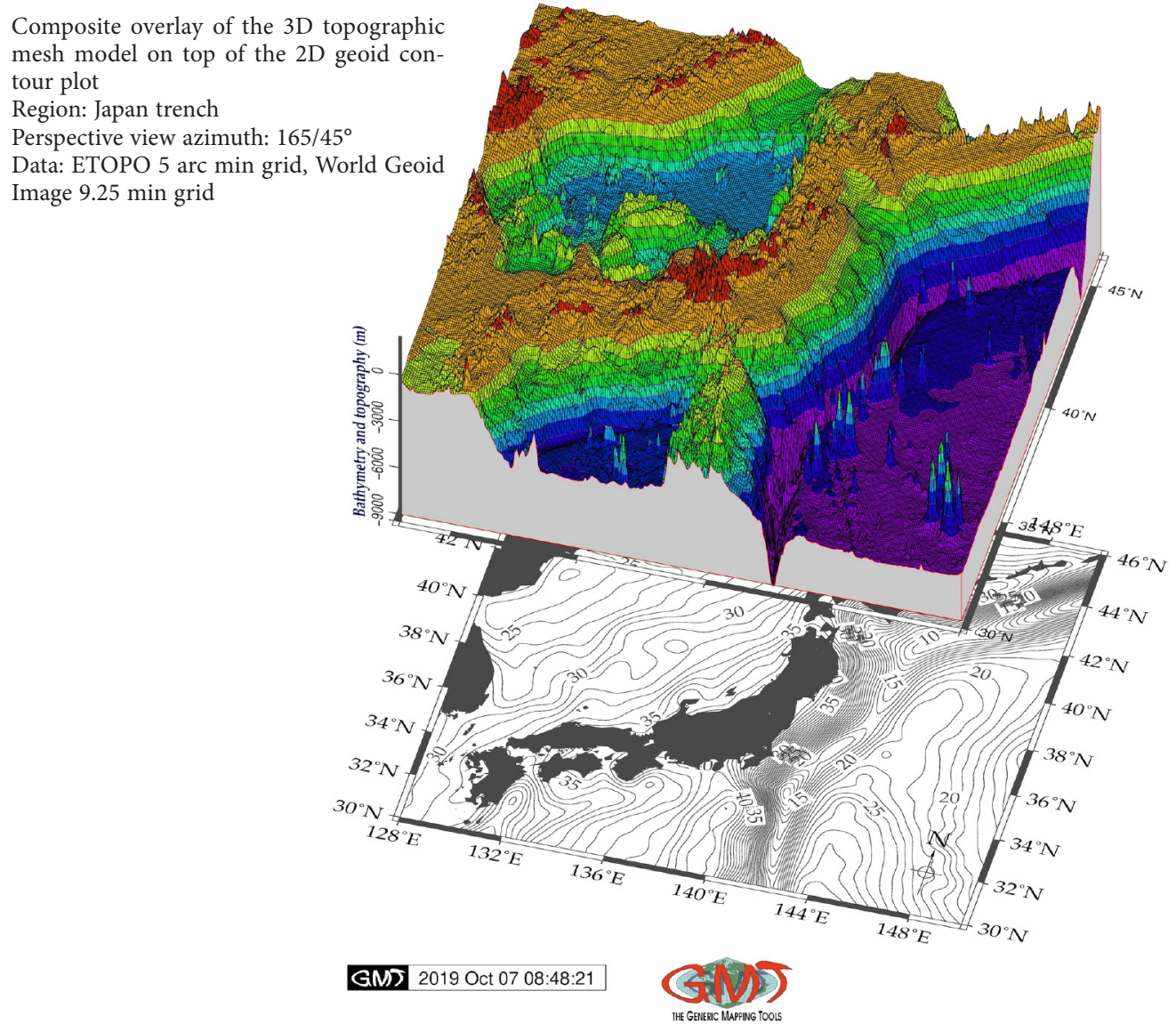

Figure 6. 3D topographic model the Japan Trench area 
with an oblique perspective view azimuth $165^{\circ} / 45^{\circ}$ and a vertical exaggeration for a three-dimensional view. The colour visualization is using deep purple for the lowest elevations in the deep-sea trench, shading to blue in the abyssal area and light blue in the shelf area and yellow-to red colours on the topographic heights for the highest elevations. Visualizations in Figure 1 and 2 show 2D maps, presenting a cartographic visualization of the study area. As such, DEMs involved the interpolating of the digital contour map that have been produced from the numerical matrix. The contour lines were generated using the GMT methods by interpolation techniques implying the continuous at each location in the modelled terrain. Among the factors affecting DEM, a crucial role for the quality of the output model have the following categories: terrain roughness, elevation data sampling density, resolution (15 arc-second for GEBCO, 1 arc-minute for ETOPO1 and 5 arc-minute for ETOPO5) interpolation algorithm which generates a new terrain dataset based on the existing data points.

\subsection{GMT methodology}

The advantages of the GMT scripting toolset comparing to the traditional GIS widely used in the geosciences (e.g. Suetova et al., 2005; Smirnoff et al., 2008; Klaučo et al., 2013, 2017; Lemenkova et al., 2012) lies in its flexibility: there are multiple options in the toolset that can be adjusted and modified by the cartographer: projections, aesthetics of the grids, fonts, map layouts, colour scale location, directions rose placement, adjustment of the titles and subtitles and selection of the vast variety of the available colour palettes. Using GMT based bathymetric data processing in the marine mapping is presented in various publications (Miura et al., 2005; Fukuda et al., 2019; Gauger et al., 2007). The direct plotting of the raster data goes through the scripting approach when a script consists of several lines of code (similar to the programming) with stepwise definition of each cartographic element that should be plotted on the map. The main difference of GMT comparing to the GIS lies in the fact that GMT has no traditional GUI and menu with commands used for mapping and visualization. Instead, GMT is based on the scripting approach, that is, all commands go from the command line similar to the sequence of codes in the programming language.

The scripting nature of GMT implies using various modules for plotting cartographic elements. The base map with general cartographic elements, such as axes, fill, titles was plotted using a module 'basemap'. A widely used Mercator projection was selected for mapping by '-JM' flag. Minor cartographic design elements, such as tick-mark intervals, annotation, and gridlines were also set up using a 'basemap' GMT module. The visualization of the images was performed using the 'grdimage' module which defines the parameters of the $2 \mathrm{D}$ raster image drawing. The visualization of the maps plotted in Figures 1 to 5 was based on the 'grdimage' module with adjusted colour palettes via the 'makecpt' module. This module enables to colour the grid according to the value of the attribute data using a variety of GMT-native colour palettes. The extent of the data range was checked by the GDAL utility 'gdalinfo' to define the minimal and maximal data and select the gradient extent.

The topographic isolines were plotted using the GMT module 'contour' where the density and graphical visualization (thickness, colour and annotations) are defined for each of the maps. The 3D model was drawn using the 'grdview' module which creates the $3 \mathrm{D}$ perspective surface mesh from a grid DEM (Figure 6). A geomorphological modelling was made using a combination of cartographic visualization modules described above and a 'grdtrack' module which sample grids at specified $(\mathrm{x}, \mathrm{y})$ locations and records elevation data at these points and creates a table that contains xyz values. This table was then used for plotting the profiles (Figure 8), plotting histograms (Figure 9) and statistical modelling to analyse a curvature (Figures 10 and 11). The histograms were plotted using a specially designed module 'histogram'. The statistical trend modelling of the curved lines was made using the GMT module 'trend1d' which enables to fit the weighted polynomial or Fourier model using the mathematical equations embedded in the module parameters (visualized in Figures 10 and 11). The conversion of the final output was made using the 'psconvert' module which converts the PostScript (ps) files to other graphical formats (e.g. JPEG) using a GhostScript.

\subsection{Cross-section transects}

The methodology for the automated digitizing of the cross-section profiles by using GMT modules 'grdtrack', 'convert' and stacking these profiles using the mean (or median), writing stacked profile into file for further processing is described by Wessel and Smith (2018). While studying submarine geomorphology of the hadal trenches, variations of the bathymetric areas can be analysed through modeling of their altitudes and roughness: steepness of the slope gradient, as visualized on Figure 10 and Figure 11. For the Japan Trench, the depth records vary between the elevated, steep and rough geomorphic structures (horsts and grabens) and more flat, gently sloping areas. This can be modelled through the technique of cross-sectioning of the trench's profiles and analysing their slope gradient.

The terrain cross-sections transecting the trench in the orthogonal directions, perpendicularly to the trench axe, represent the amplitude of the natural geomorphic shape: roughness, steepness, homogeneity of the relief. The depths variations can be seen on the median stacked profiles (Figure 8). Visualizing the cross-section transecting profiles for the precise modelling of the submarine landforms requires automatization, since the ML approaches give higher degree of accuracy while digitizing data. Experience of the ML in the semi-automatic digitizing of the raster maps has been reported in previous 


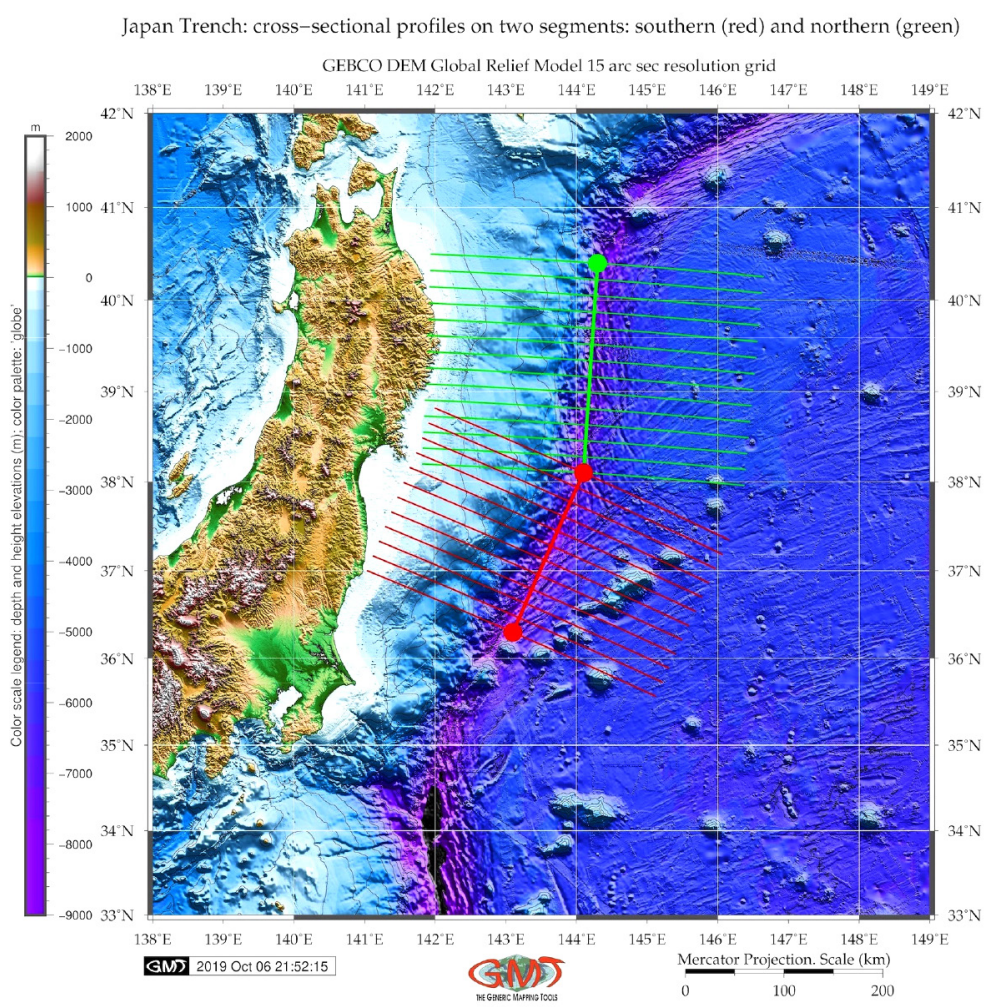

Figure 7. Visualized cross-section profiles of the two segments along the Japan Trench

works (Schenke \& Lemenkova, 2008). The GMT scripting based approach enables to do automatic digitizing of the profiles crossing the geomorphic structures in a precise and a quick way.

\subsection{Statistical analysis}

Based on the statistical analysis of the of overlaid profiles, the median profile was extracted and highlighted (red lines on Figure 8, A and B). Various cartographic elements were visualized using the GMT modules 'psbasemap', 'grdcontour', 'psscale,' 'logo', etc. Cutting necessary square of the study area was done using the 'grdcut' module. Afterwards, the raster was visualized by the 'grdimage' module using a color palette scale previously defined using a 'makecpt' GMT module. The text annotations were added on the map using the two possibilities: either by the 'pstext' module or directly by the UNIX utility 'echo'. Finally, the 'psxy' module was used for plotting the geologic lineaments and points. The output file was then converted to the graphic (e.g. jpg or tiff) using the 'psconvert' module. At the next step, the descriptive statistical analysis as histograms (Figure 9) was done using 'pshistogram' GMT module. Further description of the general GMT functionalities can be found in detailed description provided by Wessel et al. (2019). The statistical analysis is an important step in data analysis in marine geology. Many studies reported methods, approaches and algorithm to better process and model data aimed at highlighting phenomena. Examples of various methods of statistical data analysis include data visualization, regressions, correlation, inference (Roberts et al., 2019; Lemenkova, 2019d), velocity modeling using grid based travel-time calculation method (Fujie et al., 2006), regression analysis of variables (Lemenkova, 2019c), factor analysis (Tucker, 1964; Lemenkova, 2018c), clustering and data grouping (Dumont et al., 2018; Lemenkova, 2019h). As for data instruments, examples of application include R programming language (Kotov \& Pälike, 2017, 2019; Lemenkova, 2018a), Python programming language (Yu et al., 2019; Lemenkova, 2019b), SPSS Statistics (Lemenkova, 2019e), Gretl (Lemenkova, 2019d). Comparing to these studies, the advantage of the GMT scripting solutions consists in the possibility to integrate classic mapping with statistical analysis and performing spatial operations for a raster dataset. A workflow of GMT mapping includes a set of independent processes run by each corresponding module: display of images, adding legends, interpolating and plotting isolines, adding transparent layers, performing statistical analyses, cartographic projecting operations with vector data and graphical visualization of the results.

\subsection{Mathematical modelling}

To better understand the slope gradient steepness, a 'trend1d' GMT module was applied for modelling curves of the median stacked profiles (Figure 10 and Figure 11) where several mathematical formulae were used to visualize the slope steepness. Modelling trend curves (Figure 10 and Figure 11) for the northern and southern segments was based on the testing of various mathematical functions. The geophysical visualization included the geoid 

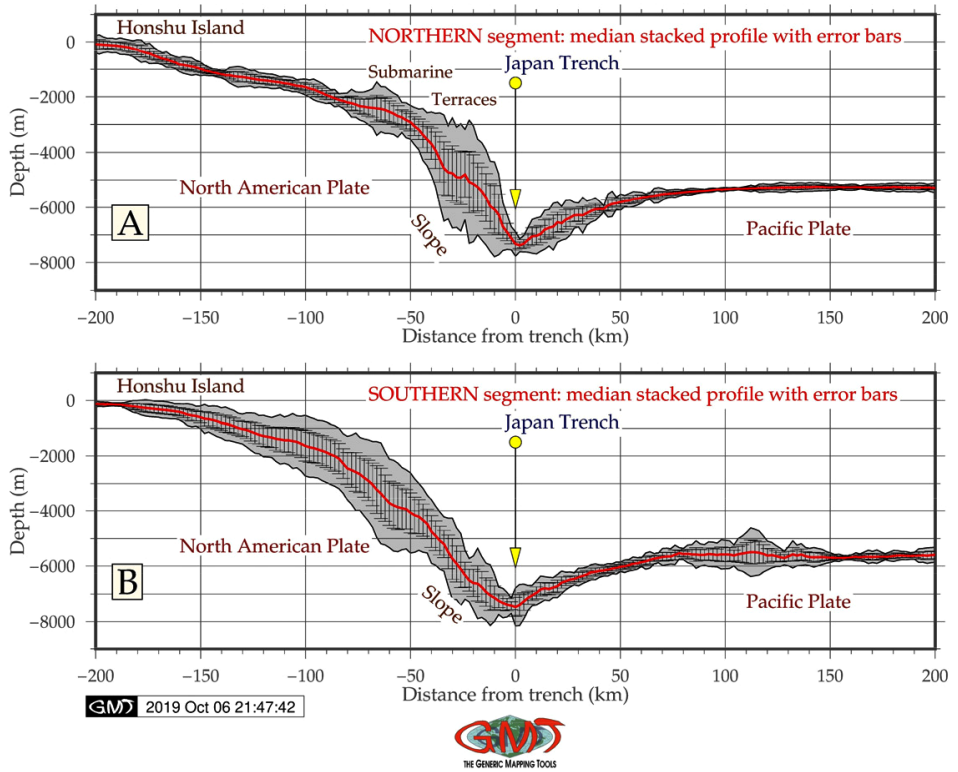

Figure 8. Graph of the modeled two segments of the Japan Trench

and free-air models covering the study area of the Japan Trench (Figure 4 and Figure 5). The data used for the visualization include the geoid grid and the marine gravity field grid from the Geosat and ERS-1 altimetry taken as available raster grids described in detail in the relevant works (Smith \& Sandwell, 1995; Sandwell et al., 2014).

\section{Results}

\subsection{Geomorphology}

Depth is a fundamental bathymetric variable showing the elevation records below the sea level reflected in the submarine geomorphology. Therefore, the geomorphic

Japan Trench: histograms on depths: northern (A) and southern (B) parts
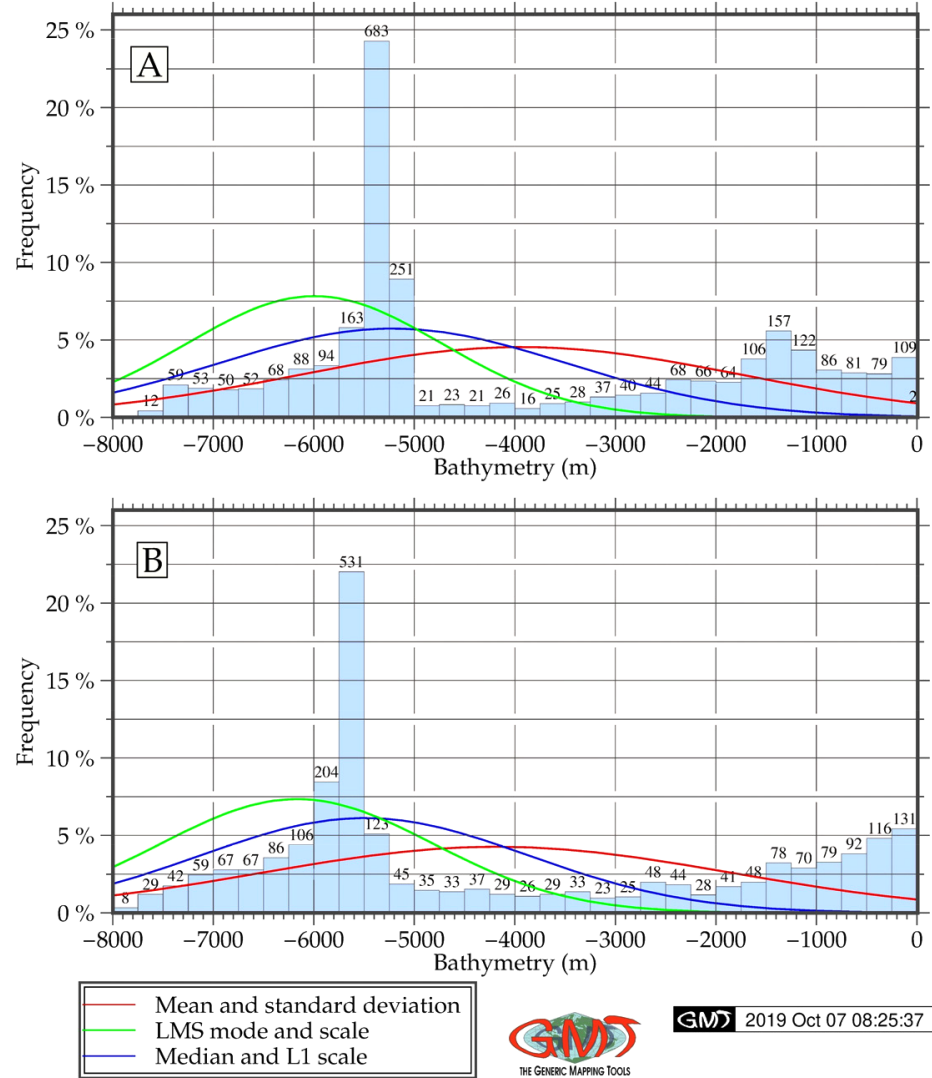
analysis of GEBCO dataset was performed for computation, comparison and descriptive statistical analysis of the depth in two segments of the Japan Trench. The comparative analysis of the depth in two parts of the series of cross-section profiles (Figure 8) revealed a steeper slope on the northern part of the trench on the continental slope part beneath the frontal wedge of the North American tectonic plate. The southern part of the trench shows a gentler slope on the Honshu Island. The location of the swath profiles traversing the two segment of the Japan Trench South-West to North-East direction is shown in Figure 7. The 12 profiles were drawn for the southern segment and the 14 profiles for the northern one.

The highly rugged geomorphological structure of the median profiles, as well as altitude increase in the S-N direction can be seen on the northern part of the trench (Figure 10). Furthermore, the results were interpreted based on the hypothesis that the geological settings and seismicity of the area impact the trench roughness and geomorphic shape. Therefore, studying bathymetric patterns and variations by the cross-sectioning profiles reveals the interplay between the geologic and topographic settings. The deep-sea trench presents a complex geological system which is shown in Figure 3: the region is notable for a high level of seismicity, repetitive earthquakes and an active volcanism. Consequently, the western part of the trench profiles (Honshu Island slope) has a steeper slope comparing to the oceanward slopes for both segments, which can also be seen on the 3D model, as shown in Figure 6.

\subsection{Statistical analysis}

The statistical analysis of the most frequent bathymetric value for the northern part of the Japan Trench
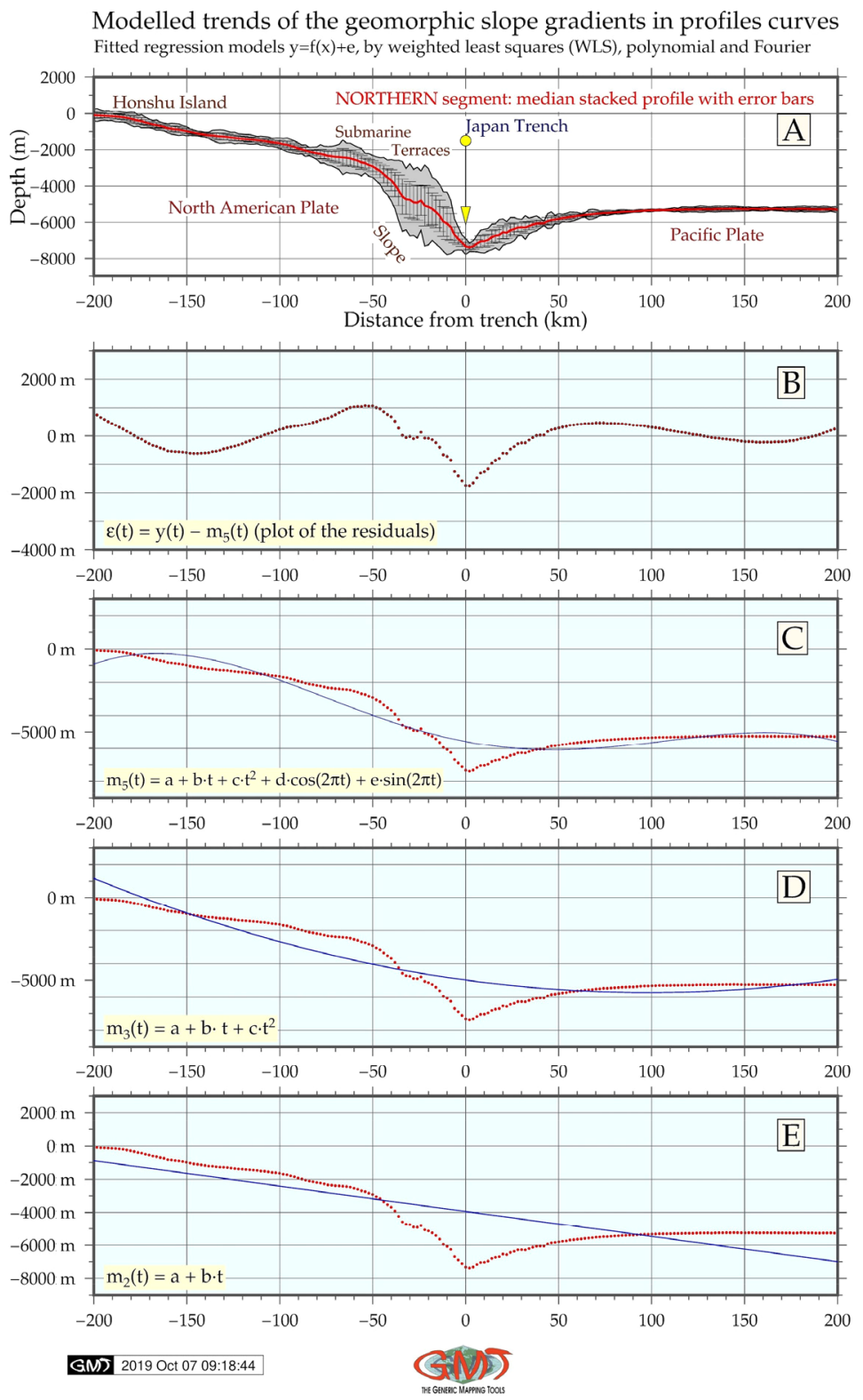

Figure 10. Mathematical approximation of the modeled trends in northern segment 
(Figure 9, A) shows a range of 5300 b.s.l. to 5500 b.s.l. $\mathrm{m}$ (683 samples recorded). As for the southern part, the most frequent depths lie within interval of -5500 to -5800 meter (531 samples detected, Figure 9, B). Comparing the deepest values of the bathymetry, one can notice the southern part to be slightly deeper: the deepest records up to 8000 b.s.l. $\mathrm{m}$ (8 samples are recorded). In total, 139 samples $(8+29+42+59)$ are located on the depths from -7000 to $-8000 \mathrm{~m}$ in the southern part of the trench (Figure $9 \mathrm{~B}$, left part of the graph). In contrast, in the northern part of the trench, the same depth range has 124 records $(12,59$ and 53 in the deepest part of the profile, Figure 9 A, left part of the graph). Furthermore, the values located on the depths from -4000 to -5000 meter are more frequent noted for the southern part of the trench: 134 records in total $(35+33+37+29$ samples, Figure 9, B), while the northern part of the trench do not overstep 100: 91 records $(21+23+21+26$ records, Figure $9, \mathrm{~A})$. To sum up, the southern part is shallower than the northern part of the trench. It shows (Figure 11) deeper values than that of the northern segment (Figure 10).

\subsection{Geophysics}

The geophysical data compiled existing gravity and geoid data, including land and satellite-derived data, for the Japan Trench region and its surroundings. Based on the dataset analysis, all data were adjusted and modelled by the GMT (Figure 4 and 5). The new maps of the free-air gravity anomalies and geoid undulations were visualized detailing the tectonics of the region. The geophysical investigation of the presented modeling of geoid (a mean sea level model) and free-air gravity anomalies reflect the density variations of the Earth in the area across the
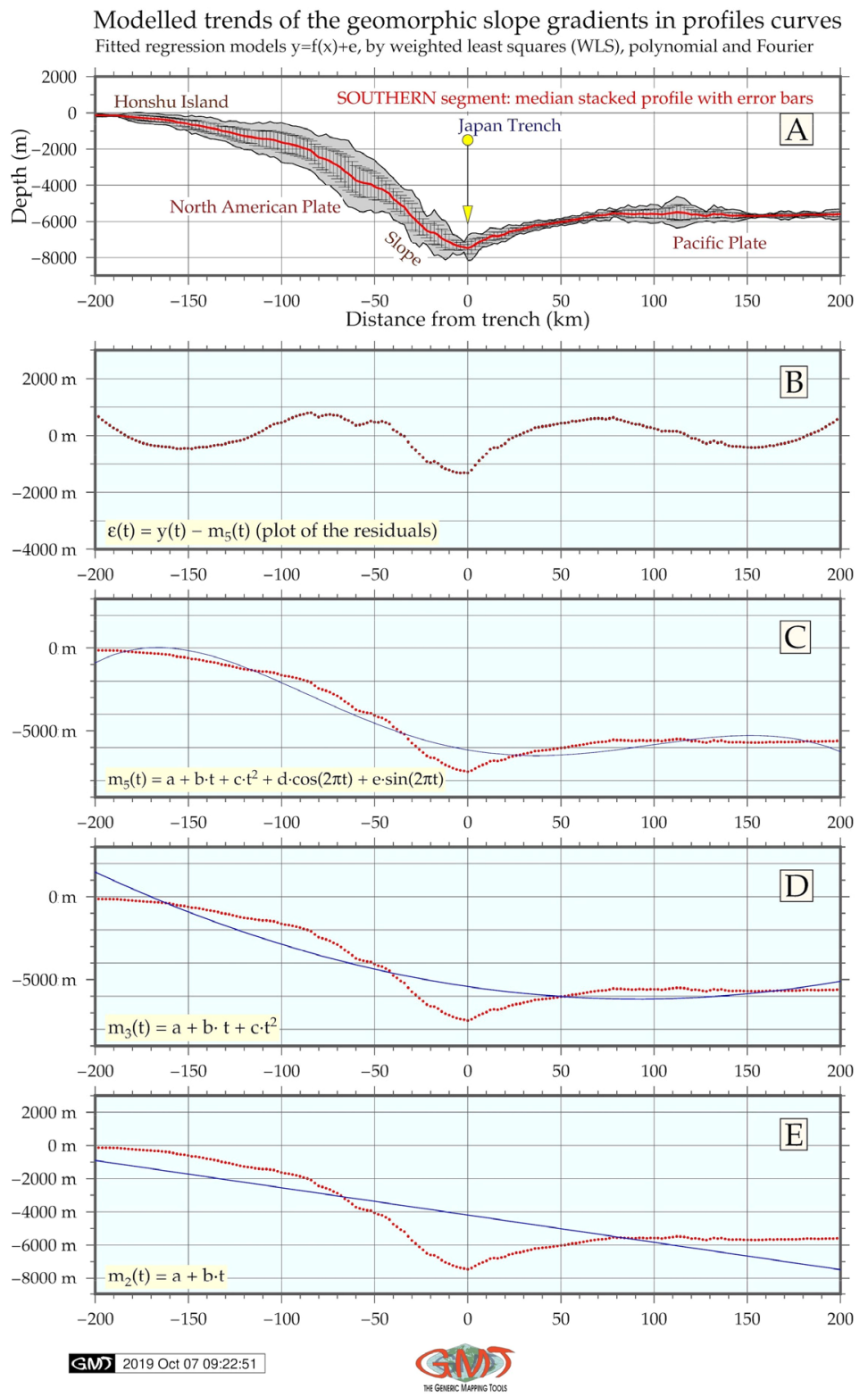

Figure 11. Mathematical approximation of the modeled trends in southern segment 
Japan Trench and surroundings (Figure 4 and Figure 5). The recorded area of the Japan Trench has the geoid values of 0-20 mGal (Figure 4) as can be clearly seen as a light green color with dense isolines.

The highest values on the geoid elevations is recorded by the Honshu Island (above $40 \mathrm{mGal}$, shown as red color on the map). The rest of the area is covered by the values in the range of $20-40 \mathrm{mGal}$, which shows moderate geoid undulations. The gravity map (Figure 5) shows density variations of the Earth's interior in the study area. The free-air model shows gravity reduction from the topographic surface to the geoid in the study area. Map of freeair gravity anomalies (Figure 5) is defined with respect to the elevation showing values below $-30 \mathrm{mGal}$ in the Japan Trench area (visualized by deep purple color on the map). The marine areas of the Sea of Japan and the Pacific Ocean have values of up to $40 \mathrm{mGal}$ of elevations. Certain areas on the Japan Islands (Honshu and Hokkaido) reach above $100 \mathrm{mGal}$ (red color on the map) showing high values in concern to gravity.

Several gravity features are highlighted by the presented maps and can be used in further studies on this region: (1) an isolated gravity high with values over $95 \mathrm{mGal}$ is located northeast off Hokkaido; (2) Along the Japan Trench gravity demonstrates strongly negative values, highly contrasting with neighboring coastal areas of Honshu (over the $100 \mathrm{mGal}$ ); (3) gravity anomaly approximation points at a significant gradient near the neighboring IzuBonin Trench of $30-34^{\circ} \mathrm{N}$; (4) In the southwestern Nankai Trough, the SW trending low-values gravity anomaly are within the range of -20 to $-60 \mathrm{mGal}$. Demonstrated variations reflect the geological local settings and tectonic evolution.

\section{Conclusions}

The deep-sea trenches are one of the most important measurable submarine features of the ocean seafloor. In this study two segments of the Japan Trench have been studied with a comparative analysis of its northern and southern parts. The GMT-based methods were used to automatically digitize a set of the cross-section profiles of the trench bathymetry based on high-resolution data grid GEBCO. The statistical and geospatial modeling methods are favorable for the bathymetric mapping, because they enable to visualize the axis of the trench bed. Using the GMT scripting enabled to rapid execute the digitizing of the profiles (Figure 7). In total, the 12 profiles on the southern segment and the 14 profiles in the northern one were modeled with a $400 \mathrm{~km}$ length, $20 \mathrm{~km}$ gap in between each two profiles and $2 \mathrm{~km}$ of the sampling dense.

The northern part of the trench has demonstrated a more complicated relief. This is caused by a higher seismic activity of the trench. On the contrary, southern part has a gentler slope on the Honshu island side. As for the absolute depths, both parts of the trench are comparable and do not overstep $-8,000$ meters. As also noticed earlier by Yamano et al. (2014), the two segments of the Japan Trench differ in a heat flow where the high and varying values are distributed on the northern half of the trench within the $150 \mathrm{~km}$ of the trench axis. This correlates with current investigations with profile width of $200 \mathrm{~km}$ to each flank of the trench (taking in total $400 \mathrm{~km}$ ). The occurrence of the anomalous heat flow along the Japan Trench correlates with the deformation of the subducting Pacific tectonic plate.

The variations in the submarine landform shapes are largely impacted by the geologic, seismic and tectonic setting, as well as environmental context of the study area (Lemenkova, 2019a). The complex relationship between the geological settings of the region, glacial and climatic factors is also illustrated by Kuhn et al. (2006). The bathymetry and the geomorphic structure of the trench is largely influenced by the tectonic processes: speed and strength of the lithospheric plates subduction, depending on the location and closeness to the tectonic plate boundaries (Lemenkova, 2019f). As a general rule, the homogeneous patterns are typical for the uniform tectonic blocks, while steep and rugged submarine landforms usually form in the complex geological situation (e.g. faults, slabs, tectonic plates boundaries), which is also affected by the glaciological processes and sedimentation (Lemenkova, 2018b; Dowdeswell \& Vásquez, 2013; Lemenkova, $2019 \mathrm{~g}$ ). Besides, the bathymetry of the seafloor correlates with the marine gravity (Marks \& Smith, 2012). As briefly demonstrated above, the complexity of the processes affecting the formation of the deep-sea trenches can only be modelled using a combination of the advanced methods of data analysis, numerical modelling and computations, statistical plotting and refined methods of cartographic mapping which presents the GMT.

Native scripting syntax of GMT supports a variety of cartographic manipulations: data management, statistical analysis, visualization graphical layout. The thematic maps presented by the GMT demonstrated print-quality graphical overlays on maps with variations in transparen$\mathrm{cy}$, cartographic design and approaches of visualization to better analyze data and geographic phenomena (tectonics, geologic lines, geophysical fields, topographic relief, etc). Using a combination of several GMT modules to conduct these operations results in effective and rapid processing that can be also extrapolated to big data: scripting solutions of GMT present reproducible research framework that enables the full traceability of the cartographic workflow.

A GMT operability with a variety of formats and a GDAL-support present its serious advantage over traditional GIS. A modular system of GMT enables to link the cartographic maps with statistical analyses in a script. Finally, the GMT is an open source toolset with a scripting language with gives a full transparency on the use of its module frameworks, methods and tools used to perform both a complex geographical analysis and a classic cartographic visualization. Because the script describes every steps of the process and records raw data and modules 
used for mapping, it can be recorded in a GitHub repository for the convenience of reuse. This paper contributed both to the regional studies of the Japan Trench geology and to the technical description of GMT-based applications with presentation of maps and modules used for plotting.

\section{Acknowledgements}

The research was funded by China Scholarship Council (CSC), State Oceanic Administration (SOA), Marine Scholarship of China, Grant No. 2016SOA002, People's Republic of China.

\section{References}

Abe, K. (1977). Tectonic implications of the large shioya-oki earthquakes of 1938. Tectonophysics, 41(4), 269-289. https://doi.org/10.1016/0040-1951(77)90136-6

Arai, K., Inoue, T., Ikehara, K., \& Sasaki, T. (2014). Episodic subsidence and active deformation of the forearc slope along the Japan Trench near the epicenter of the 2011 Tohoku Earthquake. Earth and Planetary Science Letters, 408, 9-15. https://doi.org/10.1016/j.epsl.2014.09.048

Bose, S., Saha, P., Mori, J. J., Rowe, C., Ujiie, K., Chester, F. M., Conin, M., Regalla, C., Kameda, J., Toy, V., Kirkpatrick, J., Remitti, F., Moore, J. C., Wolfson-Schwehr, M., Nakamura, Y., \& Gupta, A. (2015). Deformation structures in the frontal prism near the Japan Trench: Insights from sandbox models. Journal of Geodynamics, 89, 29-38.

https://doi.org/10.1016/j.jog.2015.06.002

Boston, B., Moore, G. F., Nakamura, Y., \& Kodaira, S. (2017). Forearc slope deformation above the Japan Trench megathrust: Implications for subduction erosion. Earth and Planetary Science Letters, 462, 26-34.

https://doi.org/10.1016/j.epsl.2017.01.005

Dowdeswell, J. A., \& Vásquez, M. (2013). Submarine landforms in the fjords of southern Chile: implications for glacimarine processes and sedimentation in a mild glacier-influenced environment. Quaternary Science Reviews, 64, 1-19. https://doi.org/10.1016/j.quascirev.2012.12.003

Dumont, M., Reninger, P. A., Pryet, A., Martelet, G., Aunay, B., \& Join, J. L. (2018). Agglomerative hierarchical clustering of airborne electromagnetic data for multi-scale geological studies. Journal of Applied Geophysics, 157, 1-9.

https://doi.org/10.1016/j.jappgeo.2018.06.020

Ferrini, V. (2018, November 28 - December 1). Briefing on the work of GEBCO (General Bathymetric Chart of the Oceans). In $19^{\text {th }}$ Meeting of the Meso American - Caribbean Sea Hydrographic Commission (MACHC), Cartagena de Indias, Colombia.

Fujie, G., Ito, A., Kodaira, S., Takahashi, N., \& Kaneda, Y. (2006). Confirming sharp bending of the Pacific plate in the northern Japan trench subduction zone by applying a traveltime mapping method. Physics of the Earth and Planetary Interiors, 157, 72-85. https://doi.org/10.1016/j.pepi.2006.03.013

Fukuda, S., Sueoka, S., Hasebe, N., Tamura, A., Arai, S., \& Tagami, T. (2019). Thermal history analysis of granitic rocks in an arc-trench system based on apatite fission-track thermochronology: A case study of the Northeast Japan Arc. Journal of Asian Earth Sciences, 1, 100005.

https://doi.org/10.1016/j.jaesx.2019.100005
Gauger, S., Kuhn, G., Gohl, K., Feigl, T., Lemenkova, P., \& Hillenbrand, C. (2007). Swath-bathymetric mapping. Reports on Polar and Marine Research, 557, 38-45.

GEBCO Committee. (2016). General Bathymetric Chart of the Oceans (GEBCO) - from the coast to the deepest trench. Hydro International. https://www.hydro-international.com/content/ article/from-the-coast-to-the-deepest-trench

Hayakawa, T., Kasahara, J., Hino, R., Sato, T., Shinohara, M., Kamimura, A., Nishino, M., Sato, T., \& Kanazawa, T. (2002). Heterogeneous structure across the source regions of the 1968 Tokachi-Oki and the 1994 Sanriku-Haruka-Oki earthquakes at the Japan Trench revealed by an ocean bottom seismic survey. Physics of the Earth and Planetary Interiors, 132, 89-104. https://doi.org/10.1016/S0031-9201(02)00046-8

Ikehara, K., Kanamatsu, T., Nagahashi, Y., Strasser, M., Fink, H., Usami, K., Irino, T., \& Wefer, G. (2016). Documenting large earthquakes similar to the 2011 Tohoku-oki earthquake from sediments deposited in the Japan Trench over the past 1500 years. Earth and Planetary Science Letters, 445, 48-56. https://doi.org/10.1016/j.epsl.2016.04.009

Ito, T., \& Ogawa, Y. (1994). Origin of ferro-manganese nodules from the Japan Trench oceanward slope. The Geographical Journal, Tokyo Geographical Society, 103, 684-695 (in Japanese with English abstract).

https://doi.org/10.5026/jgeography.103.6_684

Janssen, C., Naumann, R., Morales, L., Wirth, R., Rhede, D., \& Dresen, G. (2015). Co-seismic and/or a-seismic microstructures of JFAST 343 core samples from the Japan Trench. Marine Geology, 362, 33-42.

https://doi.org/10.1016/j.margeo.2015.01.013

Kawakatsu, H., \& Seno, T. (1983). Triple seismic zone and the regional variation of seismicity along the Northern Honshu Arc. Journal of Geophysical research: Solid Earth, 88(B5), 4215-4230. https://doi.org/10.1029/JB088iB05p04215

Klaučo, M., Gregorová, B., Stankov, U., Marković, V., \& Lemenkova, P. (2013). Determination of ecological significance based on geostatistical assessment: a case study from the Slovak Natura 2000 protected area. Central European Journal of Geosciences, 5(1), 28-42. https://doi.org/10.2478/s13533-012-0120-0

Klaučo, M., Gregorová, B., Stankov, U., Marković, V., \& Lemenkova, P. (2017). Land planning as a support for sustainable development based on tourism: A case study of Slovak Rural Region. Environmental Engineering and Management Journal, 2(16), 449-458. https://doi.org/10.30638/eemj.2017.045

Kodaira, S., No, T., Nakamura, Y., Fujiwara, T., Kaiho, Y., Miura, S., Takahashi, N., Kaneda, Y., \& Taira, A. (2012). Coseismic fault rupture at the trench axis during the 2011 TohokuOki earthquake. Nature Geoscience, 5, 646-650.

https://doi.org/10.1038/ngeo1547

Kotov, S., \& Pälike, H. (2019). Enhanced Principal Tensor Analysis as a tool for 3-way geological data reconstructions. Computers and Geosciences, 123, 161-171.

https://doi.org/10.1016/j.cageo.2018.11.001

Kotov, S., \& Pälike, H. (2017). Principal tensor analysis as a tool for paleoclimatic reconstructions. In $18^{\text {th }}$ International Association for Mathematical Geosciences Conference 2017 (p. 67). IAMG, Perth.

Kuhn, G., Hass, C., Kober, M., Petitat, M., Feigl, T., Hillenbrand, C. D., Kruger, S., Forwick, M., Gauger, S., \& Lemenkova, P. (2006). The response of quaternary climatic cycles in the South-East Pacific: development of the opal belt and 
dynamics behavior of the West Antarctic ice sheet. In K. Gohl (Ed.), Expeditionsprogramm Nr. 75 ANT XXIII/4, AWI Helmholtz Centre for Polar and Marine Research, Bremerhaven, Germany.

Kumar, M. (2013). Free "Cook Book" for gridding bathymetric data. EOS Transactions American Geophysical Union, News, 94(9), 88. https://doi.org/10.1002/2013EO090005

Lay, T., Yamazaki, Y., Ammon, C. J., Cheung, K. F., \& Kanamori, H. (2011). The 2011 MW 9.0 off the Pacific coast of Tohoku earthquake: Comparison of deep-water tsunami signals with finite-fault rupture model predictions. Earth Planets Space, 63, 797-801. https://doi.org/10.5047/eps.2011.05.030

Lemenkova, P., Promper, C., \& Glade, T. (2012, June 2-8). Economic assessment of landslide risk for the Waidhofen a.d. Ybbs Region, Alpine Foreland, Lower Austria. In Protecting Society through Improved Understanding. $11^{\text {th }}$ International Symposium on Landslides \& the $2^{\text {nd }}$ North American Symposium on Landslides \& Engineered Slopes (NASL) (pp. 279-285). Banff, Canada.

Lemenkova, P. (2018a). R scripting libraries for comparative analysis of the correlation methods to identify factors affecting Mariana Trench formation. Journal of Marine Technology and Environment, 2, 35-42.

Lemenkova, P. (2018b). Hierarchical cluster analysis by R language for pattern recognition in the bathymetric data frame: a Case study of the Mariana Trench, Pacific Ocean. Virtual Simulation, Prototyping and Industrial Design. Proceedings of the $5^{\text {th }}$ Conference, 2(5), 147-152.

Lemenkova, P. (2018c). Factor Analysis by R programming to assess variability among environmental determinants of the Mariana Trench. Turkish Journal of Maritime and Marine Sciences, 4, 146-155. https://doi.org/10.31223/osf.io/es9ka

Lemenkova, P. (2019a). An empirical study of R applications for data analysis in marine geology. Marine Science and Technology Bulletin, 8(1), 1-9. https://doi.org/10.33714/masteb.486678

Lemenkova, P. (2019b). Processing oceanographic data by Python libraries NumPy, SciPy and Pandas. Aquatic Research, 2, 73-91. https://doi.org/10.3153/AR19009

Lemenkova, P. (2019c). Testing linear regressions by StatsModel library of python for oceanological data interpretation. Aquatic Sciences and Engineering, 34, 51-60. https://doi.org/10.26650/ASE2019547010

Lemenkova, P. (2019d). Regression models by Gretl and R statistical packages for data analysis in marine geology. International Journal of Environmental Trends, 3(1), 39-59.

Lemenkova, P. (2019e). Numerical data modelling and classification in marine geology by the SPSS statistics. International Journal of Engineering Technologies, 5(2), 90-99.

Lemenkova, P. (2019f). Scatterplot matrices of the geomorphic structure of the Mariana Trench at four tectonic plates ( $\mathrm{Pa}-$ cific, Philippine, Mariana and Caroline): a Geostatistical Analysis by R. Problems of Tectonics of Continents and Oceans. Proceedings of the $51^{\text {st }}$ Tectonics Meeting, 1, 347-352.

Lemenkova, P. (2019g). Statistical analysis of the Mariana Trench geomorphology using R programming language. Geodesy and Cartography, 45(2), 57-84.

https://doi.org/10.3846/gac.2019.3785

Lemenkova, P. (2019h). GMT based comparative analysis and geomorphological mapping of the Kermadec and Tonga Trenches, Southwest Pacific Ocean. Geographia Technica, 14(2), 39-48. https://doi.org/10.21163/GT_2019.142.04

Lin, W., Byrne, T. B., Kinoshita, M., McNeill, L. C., Chang, C., Lewis, J. C., Yamamoto, Y., Saffer, D. M., Moore, J. C., Wu, H.-Y., Tsuji, T., Yamada, Y., Conin, M., Saito, S., Ito, T., Tobin, H. J., Kimura, G., Kanagawa, K., Ashi, J., Under- wood, M. B., \& Kanamatsu, T. (2016). Distribution of stress state in the Nankai subduction zone, southwest Japan and a comparison with Japan Trench. Tectonophysics, 692, 120-130. https://doi.org/10.1016/j.tecto.2015.05.008

Ludwig, W. J., Ewing, J. I., Ewing, M., Murauchi, S., Den, N., Asano, S., Hotta, H., Hayakawa, M., Asanuma, T., Ichikawa, K., \& Noguchi, I. (1966). Sediments and structure of Japan Trench. Journal of Geophysical Research, 71, 2121-2137. https://doi.org/10.1029/JZ071i008p02121

Marks, K. M. \& Smith, W. H. F. (2012). Radially symmetric coherence between satellite gravity and multibeam bathymetry grids. Marine Geophysical Research, 33, 223-227. https://doi.org/10.1007/s11001-012-9157-1

Monahan, D. (2004). GEBCO: the second century. Looking towards a general bathymetric chart. Hydro International, 8(9), 45-47.

Mayer, L., Jakobsson, M., Allen, G., Dorschel, B., Falconer, R., Ferrini, V., Lamarche, G., Snaith, H., \& Weatherall, P. (2018). The Nippon Foundation - GEBCO Seabed 2030 Project: The Quest to See the World's Oceans Completely Mapped by 2030. Geosciences, 8(2), 63.

https://doi.org/10.3390/geosciences 8020063

Miura, S., Takahashi, N., Nakanishi, A., Tsuru, T., Kodaira, S. \& Kaneda, Y. (2005). Structural characteristics off Miyagi forearc region, the Japan Trench seismogenic zone, deduced from a wide-angle reflection and refraction study. Tectonophysics, 407, 165-188. https://doi.org/10.1016/j.tecto.2005.08.001

Nakamura, Y., Kodaira, S., Miura, S., Regalla, C. \& Takahashi, N. (2013). High resolution seismic imaging in the Japan Trench axis area of Miyagi. Northeast. Jpn. Geophysical Research Letters, 40, 1713-1718. https://doi.org/10.1002/grl.50364

Ogawa, Y., Kobayashi, K., Hotta, H., \& Fujioka, K. (1997). Tension cracks on the oceanward slopes of the northern Japan and Mariana Trenches. Marine Geology, 141, 111-123. https://doi.org/10.1016/S0025-3227(97)00059-5

Rabinowitz, H. S., Savage, H. M., Plank, T., Polissar, P. J., Kirkpatrick, J. D., \& Rowe, C. D. (2015). Multiple major faults at the Japan Trench: Chemostratigraphy of the plate boundary at IODP Exp. 343: JFAST. Earth and Planetary Science Letters, 423, 57-66. https://doi.org/10.1016/j.epsl.2015.04.010

Roberts, N. M., Tikoff, B., Davis, J. R., \& Stetson-Lee, T. (2019). The utility of statistical analysis in structural geology. Journal of Structural Geology, 125, 64-73.

https://doi.org/10.1016/j.jsg.2018.05.030

Smirnoff, A., Paradis, S. J., \& Boivin, R. (2008). Generalizing surficial geological maps for scale change: ArcGIS tools vs. cellular automata model. Computers \& Geosciences, 34(11), 1550-1568. https://doi.org/10.1016/j.cageo.2007.10.013

Sandwell, D. T., Müller, R. D., Smith, W. H. F., Garcia, E., \& Francis, R. (2014). New global marine gravity model from CryoSat-2 and Jason-1 reveals buried tectonic structure. Science, 346(6205), 65-67. https://doi.org/10.1126/science.1258213

Schenke, H. W., \& Lemenkova, P. (2008). Zur Frage der Meeresboden-Kartographie: Die Nutzung von AutoTrace Digitizer für die Vektorisierung der Bathymetrischen Daten in der Petschora-See. Hydrographische Nachrichten, 25(81), 16-21.

Smith, W. H. F. (1993). On the accuracy of digital bathymetric data. Journal of Geophysical Research, 98(B6), 9591-9603. https://doi.org/10.1029/93JB00716

Smith, W. H. F., \& Sandwell, D. T. (1995). Marine gravity field from declassified Geosat and ERS-1 altimetry. EOS Transactions American Geophysical Union, 76, Fall Mtng Suppl, F156.

Stagpoole, V., Schenke, H. W., \& Ohara, Y. (2016). A name directory for the ocean floor. Eos, 97.

https://doi.org/10.1029/2016EO063177 
Suetova, I. A., Ushakova, L. A., \& Lemenkova, P. (2005). Geoinformation mapping of the Barents and Pechora Seas. Geography and Natural Resources, 4, 138-142.

Tani, S. (2017). Understanding oceans. In The UNESCO Courier (pp. 65-69). https://unesdoc.unesco.org/ark:/48223/pf0000248106

Tsuru, T., Park, J.-O., Takahashi, N., Kodaira, S., Kido, Y., Kaneda, Y., \& Kono, T. (2000). Tectonic features of the Japan Trench convergent margin off Sanriku, northeastern Japan, revealed by multichannel seismic reflection data. Journal of Geophysical Research, 105, 16403-16413.

https://doi.org/10.1029/2000JB900132

Tucker, L. R. (1964). The extension of factor analysis to three-dimensional matrices. In H. Gulliksen, \& N. Frederiksen (Eds.), Contributions to mathematical psychology (pp. 109-127). Holt, Rinehart and Winston.

von Huene, R., \& Lallemand, S. (1990). Tectonic erosion along the Japan and Peru convergent margins. Geological Society of America Bulletin, 102, 704-720. https://doi.org/10.1130/00167606(1990) 102<0704:TEATJA > 2.3.CO;2

von Huene, R., \& Culotta, R. (1989). Tectonic erosion at the front of the Japan Trench convergent margin. Tectonophysics, 160, 75-90. https://doi.org/10.1016/0040-1951(89)90385-5

Wakita, K. (2013). Geology and tectonics of Japanese islands: a review - the key to understanding the geology of Asia. Journal of Air Transport Management, 31, 75-87.

https://doi.org/10.1016/j.jseaes.2012.04.014

Weatherall, P., Marks, K. M., Jakobsson, M., Schmitt, T., Tani, S., Arndt, J. E., Rovere, M., Chayes, D., Ferrini, V., \& Wigley, R. (2015). A new digital bathymetric model of the world's oceans. Earth and Space Science, 2(8), 331-345.

https://doi.org/10.1002/2015EA000107
Wessel, P., \& Watts, A. B. (1988). On the accuracy of marine gravity measurements. Journal of Geophysical Research, 93, 393-413. https://doi.org/10.1029/JB093iB01p00393

Wessel, P., Smith, W. H. F., Scharroo, R., Luis, J. F., \& Wobbe, F. (2013). Generic mapping tools: improved version released. EOS Transactions American Geophysical Union, 94(45), 409410. https://doi.org/10.1002/2013EO450001

Wessel, P. \& Smith, W. H. F. (2018). The generic mapping tools. Version 4.5.18 technical reference and cookbook [Computer software manual]. U.S.A.

Wessel, P., Smith, W. H. F., Scharroo, R., Luis, J., \& Wobbe, F. (2019). The generic mapping tools. GMT Man pages. Release 5.4.5 [Computer software manual]. U.S.A.

Yagi, Y., Nakao, A., \& Kasahara, A. (2012). Smooth and rapid slip near the Japan Trench during the 2011 Tohoku-oki earthquake revealed by a hybrid back-projection method. Earth and Planetary Science Letters, 355-356, 94-101. https://doi.org/10.1016/j.epsl.2012.08.018

Yamano, M., Hamamoto, H., Kawada, Y., \& Goto, S. (2014). Heat flow anomaly on the seaward side of the Japan Trench associated with deformation of the incoming Pacific plate. Earth and Planetary Science Letters, 407, 196-204. https://doi.org/10.1016/j.epsl.2014.09.039

Yoshii, T. (1979). Detailed cross-section of the deep seismic zone beneath northeastern Honshu, Japan. Tectonophysics, 55, 349360. https://doi.org/10.1016/0040-1951(79)90183-5

Yu, Q.-Y., Bagas, L., Yang, P.-H., \& Zhang, D. (2019). GeoPyTool: A cross-platform software solution for common geological calculations and plots. Geoscience Frontiers, 10(4), 1437-1447. https://doi.org/10.1016/j.gsf.2018.08.001

Notations

Variables and functions

b.s.l. - below sea level;

Abbreviations

DEM - Digital Elevation Model;

ETOPO5 - 5 Arc-Minute Global Earth Topographic Model;

GEBCO - General Bathymetric Chart of the Oceans;

GIS - Geographic Information Systems;

GMT - Generic Mapping Tools;

GPS - Global Positioning System;

GSFC - Goddard Space Flight Center;

GSHHG - Global Self-consistent, Hierarchical, High-resolution Geography Database;

GUI - Graphical User Interface;

EGM96 - Earth Gravitational Model of 1996;

ML - Machine Learning;

NASA - National Aeronautics and Space Administration;

NIMA - National Imagery and Mapping Agency;

NOAA - National Oceanic and Atmospheric Administration;

WGS84 - World Geodetic System 1984. 